\section{The Nuclear Magnetic Resonance Spectra of Geometrical Isomers of 2,4-Difluoro-1,3- di-t-butylcyclodiphosph(III)azane}

\author{
Rodney Keat* and David S. Rycroft \\ Department of Chemistry, \\ University of Glasgow, U. K.
}

Edgar Niecke, Hans-Günther Schäfer, and Hans Zorn

Fakultät für Chemie der Universität Bielefeld, F. R. G.

Z. Naturforsch. 37 b, 1665-1666 (1982);

eingegangen am 17. August 1982

Cyclodiphosph(III)azane, Geometrical Isomers, NMR, Amine Elimination

A new synthetic method for the preparation of the geometrical isomers of $\left(\mathrm{FPNBu}^{t}\right)_{2}$ by amine elimination from $\mathrm{Me}_{2} \mathrm{~N}-\mathrm{P}(\mathrm{F})-\mathrm{NBu}^{t} \mathrm{SiMe}_{2}$ is described.

The ${ }^{13} \mathrm{C},{ }^{19} \mathrm{~F}$, and ${ }^{31} \mathrm{P}$ NMR investigations lead to new structural assignments.

Although alkyl [1], amino [2-4], and alkoxy [5] derivatives of cyclodiphosph(III)azanes (1) are often obtained as mixtures of cis- and trans-isomers, only one isomer of each of the halogeno derivatives (1) $(\mathrm{X}=\mathrm{F}[6], \mathrm{Cl}[7]$, and $\mathrm{Br}[8])$ has been isolated.

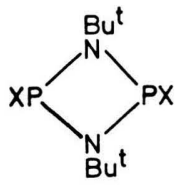

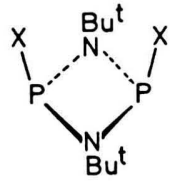

2

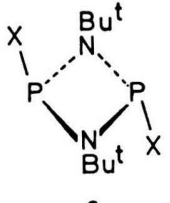

3
In the solid state $(\mathbf{1})(\mathrm{X}=\mathrm{Cl})$ has a cis-structure (2), and it has been assumed that the same structure is obtained for the analogous bromide, $(\mathbf{1})(\mathrm{X}=\mathrm{Br})$ [8].

It seems very likely that the cis-structures also exist in solution. In this connection, the ${ }^{19} \mathrm{~F}$ and 31P NMR data of the fluoride (1) $(\mathrm{X}=\mathrm{F})$ are particularly interesting, since the spectra constitute an example of an $\mathrm{AA}^{\prime} \mathrm{XX}^{\prime}$ spin system from which$\mathrm{P} \cdots \mathrm{P}, \mathrm{F} \cdots \mathrm{F}$ and other spin couplings can, in principle, be obtained.

It has been suggested that the $\mathrm{F} \cdots \mathrm{F}$ coupling in particular reflects the geometrical arrangement of the fluorine atoms [9]. Spin couplings of ca. 95 and $30 \mathrm{~Hz}$ were first assigned to ${ }^{2} J_{\left(\mathrm{PP}^{\prime}\right)}$ and ${ }^{4} J_{\left(\mathrm{FF}^{\prime}\right)}$ respectively. Unfortunately, the analysis does not distinguish between $J_{\left(\mathrm{AA}^{\prime}\right)}$ and $J_{\left(\mathrm{Xx}^{\prime}\right)}$, and the earlier assignment [5] was reversed as a result of

* Reprint requests to Dr. Rodney Keat. $0340-5087 / 82 / 1200-1665 / \$ 01.00 / 0$ comparisons with data obtained for other fluorocyclodiphosph(III)azanes. This revision is consistent with the finding [10] that ${ }^{4} J_{\left(\mathrm{F}_{\mathrm{A}} \mathrm{F}_{\mathrm{B}}\right)}$ is also relatively large $(53 \mathrm{~Hz})$ in a platinum complex of $(1)(\mathrm{X}=\mathrm{F})$. The larger coupling has since been assigned to ${ }^{2} J_{\left(\mathrm{PP}^{\prime}\right)}$ but the authors [11] appeared to be unaware of previous work in the area.

It has now been found that a mixture of geometrical isomers (2) and (3) can be obtained by the following reaction sequence:

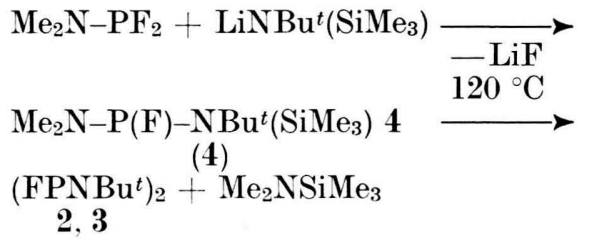

The major isomer has ${ }^{19} \mathrm{~F}$ and ${ }^{31} \mathrm{P}$ NMR shifts similar to those previously reported $[6,9]$. On standing at ambient temperature the proportion of the major isomer slowly increased. The protondecoupled ${ }^{19} \mathrm{~F}$ and ${ }^{31} \mathrm{P}$ NMR spectra of both isomers were analysed and the results are shown in the Table.

It can be deduced by inspection that ${ }^{1} J_{(\mathrm{PF})}$ (negative [12]) and ${ }^{3} J_{(\mathrm{PF})}$ are of opposite sign in both isomers. The relative signs of ${ }^{2} J_{\left(\mathrm{PP}^{\prime}\right)}+{ }^{4} J_{\left(\mathrm{FF}^{\prime}\right)}$ and ${ }^{1} J_{(\mathrm{PF})}+{ }^{3} J_{\left(\mathrm{PF}^{\prime}\right)}$ were established by a series of ${ }^{31} \mathrm{P}-\{19 \mathrm{~F}\}$ double resonance experiments. These experiment confirmed previous findings [9] for the major isomer (Table), and showed that these combinations of spin couplings were of opposite sign in the minor isomer. The combinations $\left|{ }^{2} J_{\left(\mathrm{PP}^{\prime}\right)}+{ }^{4} \boldsymbol{J}_{\left(\mathrm{FF}^{\prime}\right)}\right|$ and $\left|{ }^{2} J_{\left(\mathrm{PP}^{\prime}\right)}-{ }^{4} J_{\left(\mathrm{FF}^{\prime}\right)}\right|$ could not be distinguished in the double resonance experiments on the minor isomer as the $1.0 \mathrm{~Hz}$ splitting that was observed in the ${ }^{19} \mathrm{~F}$ spectrum was not resolved in the ${ }^{31} \mathrm{P}$ spectrum. Hence the sign of the smaller $(1.0 \mathrm{~Hz})$ coupling could not be obtained, although the $75.3 \mathrm{~Hz}$ coupling in the minor isomer was shown to be positive.

Comparison of ${ }^{13} \mathrm{C}$ and ${ }^{31} \mathrm{P}$ chemical shifts and PNC spin couplings for the two isomers with those of cyclodiphosph(III)azanes of known structure $[1-5,13,14]$ are consistent with the assignment of a cis-structure to the isomer with $\delta_{\mathrm{P}} 165.5$ as in previous work. The fact that ${ }^{2} J_{\left(\mathrm{PP}^{\prime}\right)}$ is generally small $(<20 \mathrm{~Hz})$ and negative for some trans-isomers of cyclodiphosph(III)azanes [9], indicates that the relatively large coupling of $+75.3 \mathrm{~Hz}$ must be assigned to ${ }^{4} \boldsymbol{J}_{\left(\mathrm{FF}^{\prime}\right)}$. Thus ${ }^{4} \boldsymbol{J}_{\left(\mathrm{FF}^{\prime}\right)}(=+94.4 \mathrm{~Hz})$ in the cis-isomer [2] is not necessarily dominated by a trough-space interaction [9]. Support for this viewpoint comes from the measurement of ${ }^{4} J_{(\mathrm{FF})}$ in the trans (2-trans-4-cis-6) isomer of (FPNEt) 3 where these couplings all lie in the range $10-20 \mathrm{~Hz}$ [15].

There appears to be no doubt that the cis-isomer of these halogeno-cyclodiphosph(III)azanes are thermodynamically favoured over the analogous 
Table. ${ }^{13} \mathrm{C} .{ }^{19} \mathrm{~F}$, and ${ }^{31} \mathrm{P}$ NMR data ${ }^{\mathrm{a}}$.

\begin{tabular}{|c|c|c|c|c|c|c|c|c|}
\hline Compound & $\delta_{\mathrm{P}}$ & $\delta_{\mathrm{F}}$ & $\delta_{\mathrm{NC}}$ & ${ }^{1} J(\mathrm{PF})$ & $3 J\left(\mathrm{PF}^{\prime}\right)$ & ${ }^{2} J\left(\mathrm{PP}^{\prime}\right)$ & ${ }^{4} J\left(\mathrm{FF}^{\prime}\right)$ & ${ }^{2} J(\mathrm{PC})$ \\
\hline $2 \quad(\mathrm{X}=\mathrm{F})$ & 165.5 & -23.2 & $51.6^{\mathrm{b}}$ & -1180.6 & +22.1 & +29.3 & +94.0 & $9.6^{\mathrm{d}}$ \\
\hline $3 \quad(\mathrm{X}=\mathrm{F})$ & 247.9 & -36.4 & $51.5^{\mathrm{c}}$ & -1171.3 & +20.7 & 1.0 & +75.3 & $6.3^{\mathrm{e}}$ \\
\hline
\end{tabular}

a Obtained from $\mathrm{CDCl}_{3}$ solutions at ambient temperature. References were TMS $\left({ }^{13} \mathrm{C}\right), \mathrm{CCl}_{3} \mathrm{~F}\left({ }^{19} \mathrm{~F}\right)$, and $\mathrm{H}_{3} \mathrm{PO}_{4}\left({ }^{31} \mathrm{P}\right)$; downfield shifts are positive. Spectra were obtained on a Varian XL-100 NMR spectrometer in the pulsed Fourier Transform mode, with proton-noise decoupling except for the ${ }^{31} \mathrm{P}-\left\{{ }^{19} \mathrm{~F}\right\}$ double resonance experiments. Spin couplings are in $\mathrm{Hz}$ (for the $\mathrm{AA}^{\prime} \mathrm{XX}^{\prime}$ spectra, measured from the ${ }^{19} \mathrm{~F} \mathrm{NMR}$ data). ${ }^{\mathrm{b}} \delta_{\mathrm{NCC}}=30.7$, ${ }^{3} J(\mathrm{PC})=5.9 \mathrm{~Hz},{ }^{4} J(\mathrm{FC})=1.0 \mathrm{~Hz} ;{ }^{\mathrm{c}} \delta_{\mathrm{NCC}}=30.2,{ }^{3} J(\mathrm{PC})=5.8 \mathrm{~Hz},{ }^{4} J(\mathrm{FC})=1.2 \mathrm{~Hz} ;{ }^{\mathrm{d}}{ }^{3} J(\mathrm{FC})=1.2 \mathrm{~Hz} ;$ e $3 J(\mathrm{FC})=1.8 \mathrm{~Hz}$.

trans-isomers. Whilst cis- and trans-isomers are expected to have puckered and planar ring, respectively [14], arguments relating ring conformations to thermodynamic stability are still rather speculative.

\section{Experimental}

The usual precautions in handling air and moisture sensitive compounds were observed.

\section{I. $N, N$-t-butyl(trimethylsilyl)amino-}

$N^{\prime}, N^{\prime}$-dimethylaminofluoro-phosphan (4)

$49.8 \mathrm{~g}$ (330 mmoles) Lithium-t-butyl(trimethylsilyl)amide [16] in $200 \mathrm{ml}$ diethylether were added slowly to $40.0 \mathrm{~g}$ (354 mmoles) N,N-dimethylaminodifluorophosphane [17] in $100 \mathrm{ml}$ diethylether. After stirring under reflux (about $1 \mathrm{~h}$ ) the solvent was evaporated. Vacuum distillation of the residue yields $54.2 \mathrm{~g}(69 \%)(4)$.

Calcd C45.34 H10.15 F7.97 N 11.75 P12.99, Found C46.08 H10.04 F8.30 N 11.75 P13.48. $\delta^{31} \mathrm{P} 166.3,{ }^{1} J_{\mathrm{PF}} 1042 ; \delta^{19} \mathrm{~F}-92.1 ; \delta^{29} \mathrm{Si} 3.8$, ${ }^{2} J_{\mathrm{SiP}} 9.5,{ }^{3} J_{\mathrm{SiF}} 2.0 ; \delta 1 \mathrm{H}\left(\mathrm{Me}_{2} \mathrm{~N}\right) 2.57,{ }^{3} J_{\mathrm{HP}} 8.9$ ${ }^{4} J_{\mathrm{HF}} 4.50 ; \quad\left(\mathrm{Me}_{3} \mathrm{C}\right) \quad 1.35,{ }^{4} J_{\mathrm{HP}} 1.80,{ }^{5} J_{\mathrm{HF}} 0.62 ;$ ( $\left.\mathrm{Me}_{3} \mathrm{Si}\right) 0.29,{ }^{4} J_{\mathrm{HP}} 2.38,{ }^{5} J_{\mathrm{HF}} 0.26$.

IR $(1500>\tilde{v}>800): 1481 \mathrm{~m}, 1450 \mathrm{~m}, 1401 \mathrm{~m}$. $1392 \mathrm{~m}, 1362 \mathrm{st}, 1278 \mathrm{~m}, 1265 \mathrm{sh}, 1252 \mathrm{vst}, 1191$ vst. $1140 \mathrm{w}, 1058 \mathrm{~m}, 947 \mathrm{st}, 915$ vst, 896 vst, $866 \mathrm{~m}$. 843 vst, $825 \mathrm{sh} \mathrm{cm}^{-1}$.

\section{2,4-Difluoro-1,3-di-t-butyl- cyclodiphosph(III)azanes $(\mathbf{2}, \mathbf{3})$}

$23.8 \mathrm{~g}$ (100 mmoles) (4) were pyrolised $2 \mathrm{~h}$ at $110{ }^{\circ} \mathrm{C}$. Volatile products were condensed $\left(-78^{\circ} \mathrm{C}\right)$ and sublimed again $\left(40{ }^{\circ} \mathrm{C} / 0.05\right.$ Torr $)$. Yield: $4,8 \mathrm{~g}$ $(40 \%)$.

Calcd C39.67 H7.49 F 15.59 N 11.57 P25.58, Found C38.65 H7.93 F 14.90 N 10.67 P26.13.

$\mathrm{MS}: m / e=242 \mathrm{M}^{+}(35 \%), 227 \mathrm{M}^{+}-\mathrm{Me}(94 \%) \ldots 106$ $\mathrm{Me}_{2} \mathrm{NCNPF}(100 \%) \ldots$
[1] O. J. Scherer and G. Schnabl, Angew. Chem. 88, 845 (1976); Angew. Chem. Int. Ed. Engl. 15, 772 (1976).

[2] R. Keat, D. S. Rycroft, and D. G. Thompson, J. Chem. Soc., Dalton Trans. 1980, 322 .

[3] O. J. Scherer and W. Glässel, Chem. Ber. 110, 3874 (1977).

[4] W. Zeiss, Ch. Feldt, J. Weis, and G. Dunkel, Chem. Ber. 111, 1180 (1978).

[5] R. Keat, D. S. Rycroft, and D. G. Thompson, J. Chem. Soc., Dalton Trans. 1979, 1224.

[6] J. F. Nixon and B. Wilkins, Z. Naturforsch. 25 b, $649(1970)$.

[7] O. J. Scherer and P. Klusmann, Angew. Chem. 81, 743 (1969); Angew. Chem. Int. Ed. Engl. 8, 752 (1969).

[8] K. W. Muir, J. Chem. Soc., Dalton Trans. 1975, 259 .
[9] R. Keat and D. G. Thompson, J. Chem. Soc. Dalton Trans. 1978, 634.

[10] J. C. T. R. Burckett St. Laurent, H. E. Hosseini, J. Sinclair, and J. F. Nixon, Inorg. Chim. Acta 44, L 17 (1980).

[11] J. S. Jessup, R. T. Paine, and C. F. Campana, Phosphorus and Sulphur, 9, 279 (1981).

[12] R. R. Dean and W. McFarlane, Chem. Commun. 1967,840 .

[13] E. Niecke, W. Flick, and S. Pohl, Angew. Chem. 88, 305 (1976); Angew. Chem. Int. Ed. Engl. 15, 309 (1976).

[14] R. Keat, Top. Curr. Chem. 102, in press (1982).

[15] D. A. Harvey, R. Keat, and D. S. Rycroft, submitted for publication.

[16] I. Schuhmann-Ruidisch, W. Kalk, and R. Brüning, Z. Naturforsch. 23b, 307 (1968).

[17] R. Schmutzler, Inorg. Chem. 3, 415 (1964). 